Eventos 



\title{
Projeto Justiça Terapêutica ${ }^{\star}$
}

\author{
Hugo Leonardo Rodrigues Soares $\star$ \\ Hérica Cristina Batista Gonçalves $\star \star \star ~$

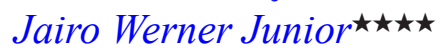

\section{Palavras-chaves: Justiça Terapêtica; Dependência Química; Medidas Sócio-educativas}

Introdução: a utilização de drogas de abuso tem se tornado uma situação corriqueira que assola a sociedade atual, não se restringindo apenas há alguns grupos, mas vem se expandindo progressivamente em todas as faixas etárias, níveis e classes sociais. Essa prática, frequentemente, está correlacionada com o aumento da incidência da criminalidade. Apesar de todas as tentativas de reverter a situação, principalmente com o uso da repressão pelo sistema jurídico, tais tentativas se mostraram ineficazes para a solução do problema em questão. No ano de 1996 e 1997, no estado do Rio Grande do Sul, foi criado a partir de vários estudos, o "Projeto Consciência", que integrou especialistas de saúde, assistência social e operadores do direito e gerou um programa do Ministério Público de atenção e informações sobre drogas nos planos jurídico e de saúde para os municípios. A partir de 1999, houve a primeira grande parceria com o Poder Judiciário do Estado do Rio Grande do Sul. Sendo assim, é nesse contexto que surge uma nova proposta, o conceito de "Justiça Terapêutica", a qual pode ser compreendida como um conjunto de medidas que visam aumentar a possibilidade de que infratores usuários e dependentes de drogas (lícitas e ilícitas) entrem e permaneçam em tratamento, modificando seus anteriores comportamentos delituosos para comportamentos socialmente adequados. O conceito de justiça engloba os aspectos do direito, legais e sociais, enquanto o termo terapêutica, relativo à ciência médica, define tratamento e reabilitação de uma situação patológica. Assim sendo, a nomenclatura Justiça Terapêutica consagra os mais altos princípios do direito na inter-relação do Estado e do cidadão, na busca da solução não só do conflito com a lei, mas conjugadamente aos problemas sociais de indivíduos e

\footnotetext{
$\star$ Trabalho apresentado na $29^{\text {a }}$ Semana Científica da Faculdade de Medicina da UFF, realizada em 30 de novembro e 1 de dezembro de 2006, no Hospital Universitário Antônio Pedro, Niterói, Rio de Janeiro.

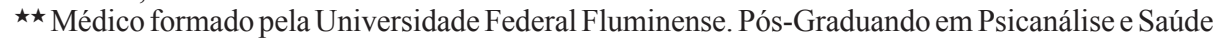
Mental pela UERJ. Ex-monitor das disciplinas de Neuropsiquiatria Infantil e Desenvolvimento Infantil. Especialista em Dependência Química pela UNIFESP/EPM. Pòs-Graduado (lato sensu) Políticas, Instituições e Saúde Mental e Vigilância Sanitária. Fiocruz/Ensp. E-mail: hlsoares@brfree.com.br

$\star \star \star$ Psicóloga, residente em Saúde Mental do Instituto Municipal Philippe Pinel. E-mail: hericacris@yahoo.com.br

$\star \star \star \star$ Orientador e professor adjunto IV, responsável pela área de Psiquiatria da Infância e Adolescência da Faculdade de Medicina (Departamento Materno Infantil) do Centro de Ciências Médicas da UFF. Médico e Doutor em Saúde Mental -UNICAMP e Mestre em Educação - UFF. Endereço: Departamento Materno-Infantil - Faculdade de Medicina Hospital Universitário Antônio Pedro (HUAP) - Rua Marquês do Paraná, 303, Centro, Niterói - RJ, CEP 24303-900.

E-mail: jairowerner@globo.com
} 
da coletividade, nas doenças relacionadas ao consumo de drogas Essa é uma forma inovadora que promotores de justiça e juizes, juntamente com profissionais da área de saúde, como psiquiatras e psicólogos, dispõem para enfrentarem um velho problema: o que fazer com as pessoas que praticam pequenos delitos onde haja o envolvimento e a dependência de drogas. Objetivo: o presente trabalho tem como objetivo apresentar os resultados alcançados pelo Projeto da Justiça Terapêutica (PJT) na unidade do GEAL/ UFF em parceria com o IPHEM (Instituto de Pesquisa Heloísa Marinho). Metodologia: Foi realizada uma pesquisa retrospectiva com 36 prontuários de usuários encaminhados pelo Ministério Público para o Projeto Justiça Terapêutica na unidade do GEAL/IPHEM, no período de 2002 a 2005. Resultados e Conclusões: Alguns dados já demonstram a efetividade do Programa quando comparado às medidas impostas anteriormente: $65 \%$ de reincidência comparado a $85 \% ; 17 \%$ dos usuários se mantiveram em abstinência durante o tratamento; $15 \%$ de alta satisfatória (abstinência, redução de danos, tempo cumprido). O Programa da Justiça Terapêutica propõe a resolução de dois problemas que precisam ser enfrentados simultaneamente: a infração à lei e uma enfermidade, ou seja, a dependência química. Logo, são questões que levam tempo para apresentarem o resultado desejado, além de requerer vontade por parte do usuário e incentivo da família. A Justiça Terapêutica é um novo paradigma para o enfoque e o enfrentamento da problemática das drogas. 